\title{
Luxação congênita do joelho no nascimento - Um caso extraordinário de redução espontânea*
}

\section{Congenital Knee Dislocation at Birth - An Extraordinary Case of Spontaneous Reduction}

\author{
Abilash Kumar $^{10}$ Manohar Arumugam ${ }^{1(0)}$ Nor Azuatul $^{2}$ Kamariah Noor ${ }^{2}{ }^{(0)}$ \\ 1 Departamento de Cirurgia Ortopédica, Universidade Putra Malaysia, \\ Serdang, Selangor, Malásia \\ ${ }^{2}$ Departamento de Cirurgia Ortopédica, Hospital Tengku Ampuan \\ Afzan, Kuantan, Pahang, Malásia \\ Endereço para correspondência Kamariah Noor, MD, MS, \\ Departamento de Cirurgia Ortopédica, Hospital Tengku Ampuan \\ Afzan, Jalan Tanah Putih, 25100, Kuantan, Pahang, Malásia \\ (e-mail: kamariahnor@yahoo.com).
}

Rev Bras Ortop 2023;58(1):164-167.

\section{Resumo \\ Palavras-chave \\ - luxações articulares/ congênitas \\ - luxações articulares/ terapia \\ - remissão espontânea \\ - recém-nascido}

A luxação congênita do joelho (LCJ) é uma malformação rara caracterizada por deformidade de hiperextensão do joelho com deslocamento anterior da tíbia, presente ao nascimento. Raramente relatada, a LCJ pode ocorrer como uma deformidade isolada ou comumente associada a anormalidades musculoesqueléticas, sendo as mais comuns a displasia do desenvolvimento do quadril (DDQ) e o pé torto congênito (PTC). A etiologia é desconhecida, mas a LC foi associada a certos fatores intrínsecos e extrínsecos. O tratamento com métodos conservadores em um estágio inicial tem maior probabilidade de produzir resultados bem-sucedidos. Relatamos aqui um caso raro de redução espontânea bem-sucedida de LC] em um bebê nas suas primeiras 24 horas de vida.

Congenital knee dislocation (CKD) is a rare malformation characterized by hyperextension deformity of the knee with anterior tibia displacement, present at birth. Rarely reported, CKD might occur as an isolated deformity or commonly associated with musculoskeletal abnormalities, with the most common ones being developmental dysplasia of the hip (DDH) and clubfoot. The etiology is unknown, but CKD has been associated with certain intrinsic and extrinsic factors. Treatment with conservative methods at an early stage is most likely to yield successful results. We report here a rare case of successful spontaneous reduction of CKD in an infant within 24 hours of life.

\footnotetext{
Trabalho desenvolvido junto à Ortopedia do Departamento de Cirurgia Ortopédica da Universidade Putra Malaysia, Serdang, Selangor, Malásia.
}

recebido 29 de Março de 2020 aceito

06 de Julho de 2020 article Publicado on-line Dezembro 22, 2020
DOI https://doi.org/ $10.1055 / \mathrm{s}-0040-1718512$ ISSN 0102-3616.

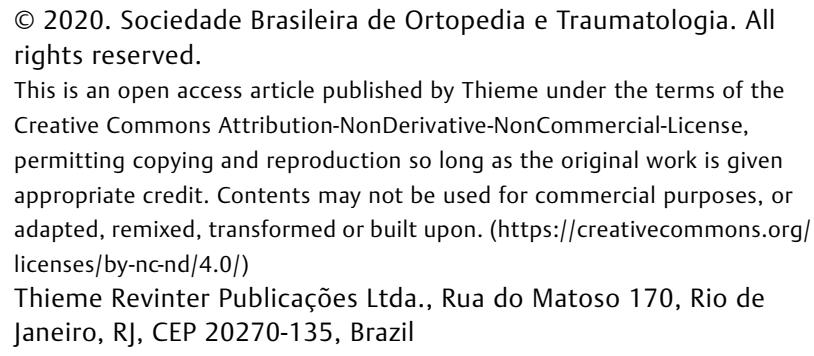

(c) 2020. Sociedade Brasileira de Ortopedia e Traumatologia. All rights reserved.

This is an open access article published by Thieme under the terms of the Creative Commons Attribution-NonDerivative-NonCommercial-License, permitting copying and reproduction so long as the original work is given appropriate credit. Contents may not be used for commercial purposes, or adapted, remixed, transformed or built upon. (https://creativecommons.org/ licenses/by-nc-nd/4.0/) Thieme Revinter Publicações Ltda., Rua do Matoso 170, Rio de Janeiro, RJ, CEP 20270-135, Brazil 


\section{Introdução}

A luxação congênita do joelho (LCJ) foi descrita pela primeira vez por Chanssier em 1812 com uma incidência relatada de 0,017 em 1.000 nascidos vivos com indistinguibilidade entre os joelhos direito e esquerdo, afetando principalmente meninas. A LCJ pode ser uma deformidade isolada; no entanto, de 40 a $100 \%$ dos pacientes têm anormalidades musculoesqueléticas associadas, sendo as mais comuns displasia do desenvolvimento do quadril (DDQ) e pé torto congênito. Outros são espinha bífida, fenda palatina, síndrome de Larsen, artrogripose, hipoplasia da fíbula, luxação do cotovelo, e deformidades da caixa torácica. ${ }^{1}$ A característica patognomônica da LCJ é a fibrose e o encurtamento do músculo quadríceps com hipoplasia da bolsa suprapatelar.

A etiologia ainda não é conhecida; entretanto, a LCJ tem sido associada a certos fatores, incluindo fatores extrínsecos, como distúrbios de empacotamento intrauterino, apresentações fetais pélvicas, desequilíbrios neuromusculares, e fatores intrínsecos como malformação genética. No entanto, três teorias diferentes foram descritas com relação a esta entidade escassa.

A primeira teoria, a teoria embriológica primária, explica outras deformidades adicionais que acompanham o problema do joelho. A segunda teoria, que é a teoria mecânica, explica que a deformidade se origina da postura fetal anormal durante o período intrauterino. A terceira e última teoria é a teoria do defeito mesenquimal que causa o músculo quadríceps fibrótico. $^{2}$

Leveuf e Pais classificara, a LCJ em três graus. ${ }^{3} 0$ grau 1 é o tipo mais comum e representa a hiperextensão congênita da articulação do joelho ao nascimento. De 15 a 20 graus de hiperextensão podem ser detectados e a amplitude passiva de flexão é de no máximo 90 graus. Grau 2, subluxação congênita com incongruência articular. A flexão passiva do joelho é impossível e hiperextensão de 25 a 40 graus é alcançada. Grau 3, representa o deslocamento total da epífise tibial anterior aos côndilos femorais, sem contato entre as superfícies articulares da tíbia e do fêmur.

O diagnóstico de LCJ é estabelecido ao nascimento pela posição clássica de genu recurvatum. Uma dobra cutânea transversal profunda é encontrada anteriormente com côndilos femorais proeminentemente palpáveis na fossa poplítea. ${ }^{4}$ A patela está profundamente colocada e geralmente não é palpável ou pode estar ausente. Haverá rotação externa aparente do membro e deformidade em valgo da tíbia. 0 exame ultrassonográfico pré-natal pode identificar a LCJ.

Bebês com LCJ devem ser diagnosticados e tratados imediatamente após o nascimento. A gestão é principalmente conservadora com redução direta e tração manual suave e persistente com gesso seriado com aumento da flexão. A flexão forçada é estritamente proibida, pois pode levar a fraturas iatrogênicas, dano epifisário e comprometer a vascularização do membro. 0 gesso deve ser trocado em série a cada 2 semanas até que a redução seja alcançada. Se e quando o gesso falhar, o tratamento cirúrgico consiste em quadriceplastia, mini tenotomia do quadríceps aberta, banda iliotibial (IT) e liberação capsular e avanço do ligamento cruzado anterior (LCA). ${ }^{5}$ No entanto, é importante que em anomalias musculoesqueléticas associadas concomitantes, o joelho seja sempre manipulado e tratado primeiro, antes do pé ou do quadril.

\section{Relato de Caso}

Um recém-nascido foi encaminhado pelo pediatra à equipe de ortopedia devido a um joelho esquerdo hiperextendido após o parto por meio de uma cesariana de emergência de incisão inferior, com uma idade gestacional de 37 semanas devido a pré-eclâmpsia materna e sofrimento fetal em trabalho de parto. $\mathrm{O}$ bebê nasceu com a cabeça primeiro e não houve complicações intraoperatórias relatadas. Seu peso de nascimento foi $2,18 \mathrm{~kg}$ e nasceu com um índice de Apgar de $8 / 9$.

Ela exibia características típicas associadas à LCJ no joelho esquerdo. $O$ exame físico revelou hiperextensão do joelho de $\sim 70$ graus com prega anterior do joelho (-Fig. 1). A flexão passiva era de 5 a 10 graus. A criança não apresentava outras malformações congênitas, como pés tortos congênitos, DDQ ou espinha bífida. As radiografias do joelho esquerdo mostraram a tíbia deslocada anteriormente ao longo eixo do fêmur (-Fig. 2). À palpação do joelho esquerdo, a patela estava colocada profundamente e notou-se que esta era menor em comparação com a direita. A criança foi diagnosticada com uma LCJ de grau II unilateral (joelho esquerdo).

Aconselhamos os pais quanto à manipulação em série com gesso e começamos com a imobilização inicial do membro

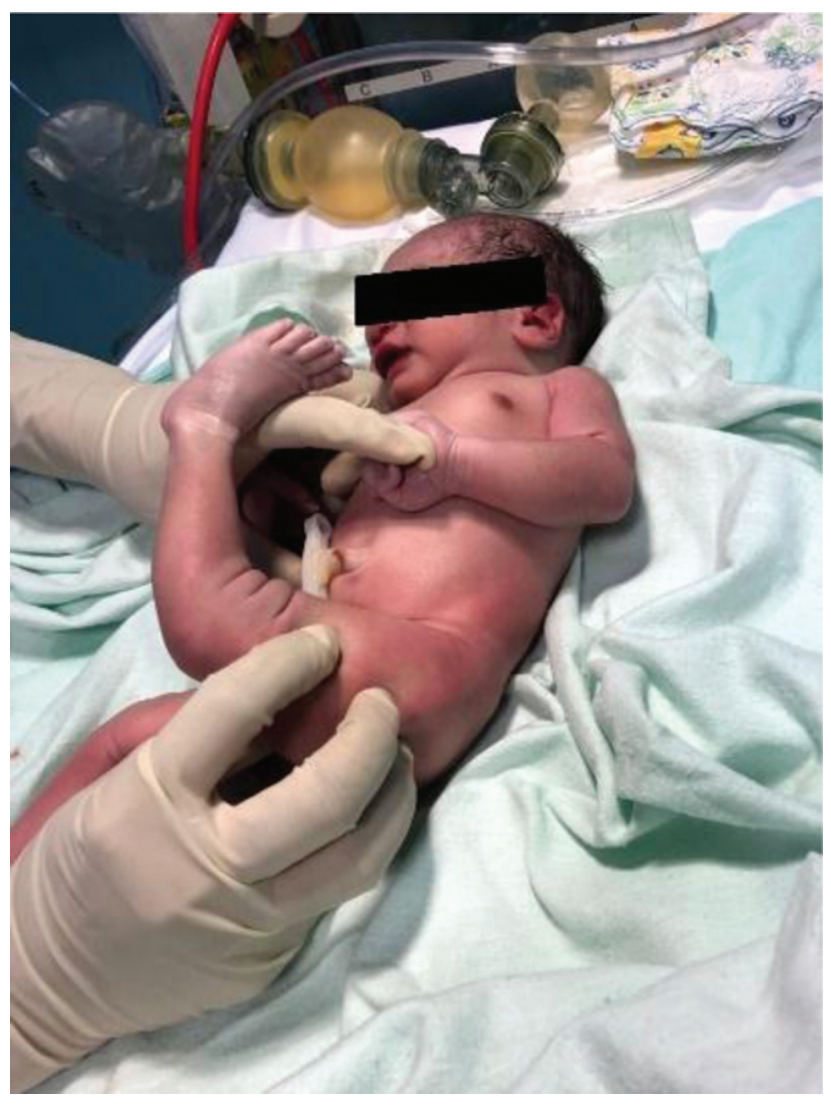

Fig. 1 Mostrando hiperextensão do joelho esquerdo em 90 graus. 


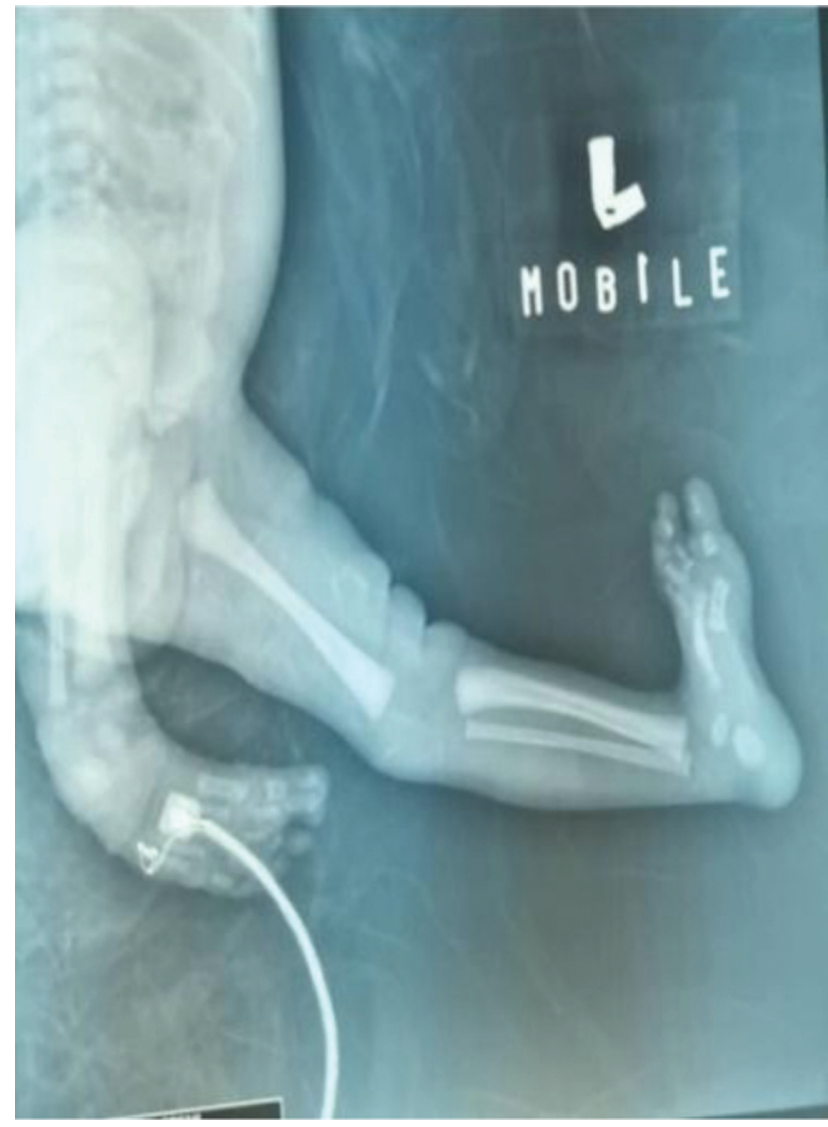

Fig. 2 Mostrando visão anteroposterior do membro inferior esquerdo.

em flexão de 5 a 10 graus. Ela foi então monitorada de perto na unidade de terapia intensiva neonatal (UTIN) com observação rigorosa da circulação. Uma hora depois, o membro inferior esquerdo estava azulado, frio e a saturação do oxigênio no sangue (SpO2) não era detectável nos dedos do pé esquerdo. Os pulsos tanto da artéria dorsal do pé (ADP) quanto da artéria tibial posterior (ATP) não eram palpáveis. Decidiu-se então remover todas as formas de talas externas e bandagens e observar o membro. Os pulsos retornaram e o membro foi novamente bem perfundido após a remoção da tala.

No dia seguinte, durante o exame, o joelho esquerdo estava em uma posição normal. A paciente tinha uma amplitude de movimento ativa de -10 graus a 120 graus. Os pulsos do membro eram fortes e iguais aos do membro contralateral. $O$ joelho esquerdo foi reduzido espontaneamente em um período de 24 horas (-Fig. 3). Decidimos abandonar nosso plano inicial de manipulação e imobilização. A criança foi colocada em um regime de fisioterapia para exercícios de amplitude de movimento do joelho esquerdo. Não foi necessário trabalho adicional de imagem.

Revisamos a criança após uma semana e, aos 8 meses de idade, não havia evidência de recorrência. A criança, entretanto, tinha o joelho esquerdo frouxo, com uma amplitude de movimento de -10 a 120 graus. Ela ainda está sob nosso acompanhamento de rotina.

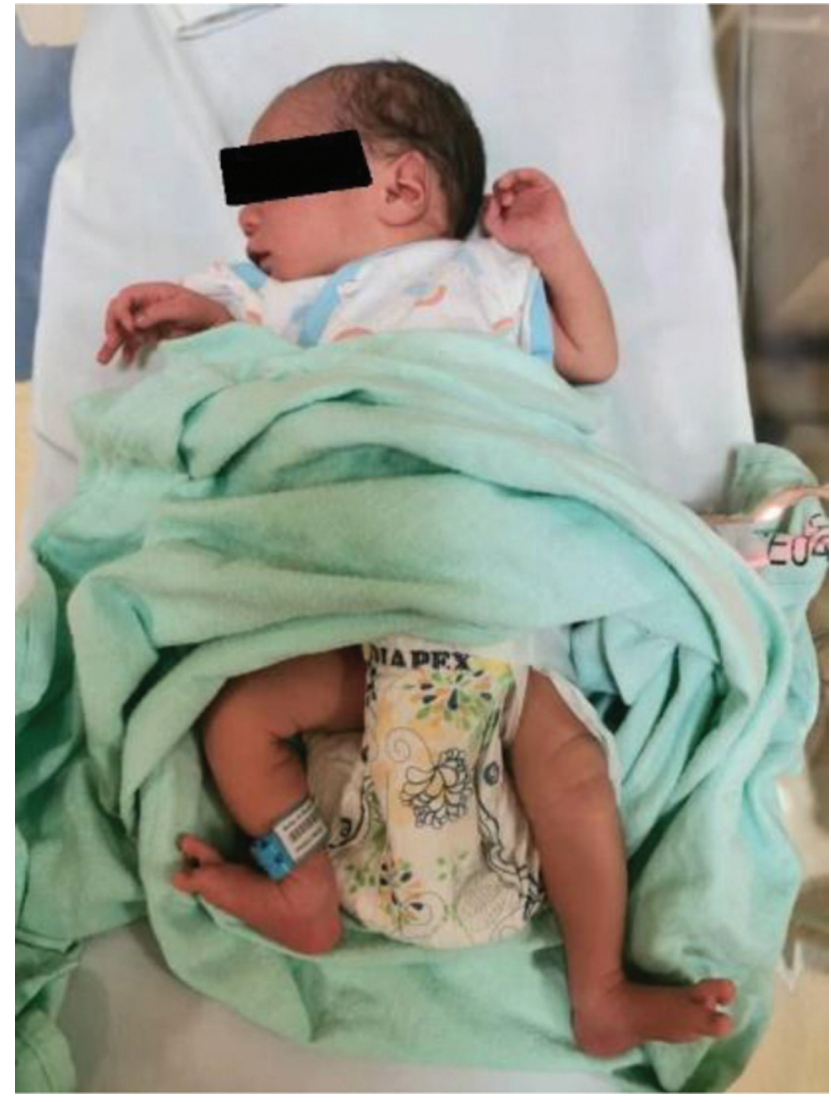

Fig. 3 Mostrando redução espontânea do joelho esquerdo nas primeiras 24 horas após o nascimento.

\section{Discussão}

A LCJ é uma anomalia musculoesquelética rara (com proporção de 17 em 1 milhão de nascidos vivos), mais frequentemente associada a outras patologias e síndromes. 0 diagnóstico de condições associadas e envolvimento sindrômico ajuda no manejo adequado e na predeterminação do resultado. Com outras deformidades associadas do quadril e do pé, o tratamento geral torna-se mais árduo e a redução das luxações do joelho deve sempre ter prioridade.

A base do tratamento para $\mathrm{LCJ}$ é a redução não cirúrgica precoce. Deve-se evitar o uso de qualquer força que possa levar à deformidade tibial, fraturas, separação fisária e comprometer a circulação distal do membro.

A literatura defende que as $L C J$ simples não sindrômicas respondem bem ao tratamento conservador com imobilização em série e geralmente têm um melhor prognóstico em comparação com as LCJs com anomalias associadas. É importante ressaltar que a família deve estar sempre informada sobre as complicações previstas da LCJ, como artrose precoce, atraso de extensão, fraqueza na extensão ou possíveis problemas de joelho no futuro. O diagnóstico precoce desta deformidade é vital, pois iniciar o tratamento o mais cedo possível promete um bom resultado.

\section{Conflitos de Interesse}

Os autores não têm conflitos de interesse a declarar. 


\section{Referências}

1 Naik PV. Management of congenital knee dislocation. Curr Orthop Pract 2013;24(01):43-48

2 Katz MP, Grogono BJ, Soper KC. The etiology and treatment of congenital dislocation of the knee. J Bone Joint Surg Br 1967;49 (01):112-120

3 Elmadaç M, Ceylan HH, Erdil M, Imren Y, Bilsel K, Tuncay I. Konjenital diz dislokasyonu. Eur J Gen Med 2013;10(03):164-166
4 Johnson E, Audell R, Oppenheim WL. Congenital dislocation of the knee. J Pediatr Orthop 1987;7(02):194-200

5 Kaissi AA, Ganger R, Klaushofer K, Grill F. The management of knee dislocation in a child with Larsen syndrome. Clinics (São Paulo) 2011;66(07):1295-1299 